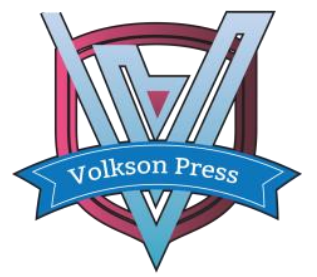

Contents List available at VOLKSON PRESS

Economics \& Management Innovations(EMI)

DOI : http://doi.org/10.26480/icemi.01.2017.206.207

\title{
Managing work of specialist technical language classes.
}

\author{
Jan Tyburski, University of Warmia and Mazury in Olsztyn, Poland \\ Department of Foreign Languages \\ email: jantyburski@wp.pl \\ This is an open access article distributed under the Creative Commons Attribution License, which permits unrestricted use, distribution, and reproduction in any \\ medium, provided the original work is properly cited.
}

\section{ARTICLE DETAILS}

\section{Article History:}

Received 02 october 2017 Accepted 06 october 2017 Available online 11 october 2017

\section{Keywords:}

work management, teaching students, technical English,

future work, job market.

\section{ABSTRACT}

The task of each school, let alone a university is to prepare graduates in the best possible way for the needs and requirements of a future job. One of the sought-after requirements of employers is a knowledge of English as a global language. A knowledge of English gives an opportunity to read professional, scientific literature, to learn the newest achievements in technology. In some technical positions a good command of English is simple indispensable. In this day and age, when numerous firms are international or cooperate closely with foreign enterprises, a knowledge of English is simply a must.Polish students are becoming more and more aware of the demand on the job market and try hard to fulfil these requirements. This consciousness is expressed explicitly in the progress they make which in turn is shown in their grades. For many years the upward trend in the achievement is evident, and finding a job candidate with a workable knowledge of English is not a problem any more. What is even of a greater importance to perspective employers, these candidates often know a specialist terminology, which enables them to work in a foreign-language environment.

\section{Introduction}

Being perfectly aware of the importance of the knowledge of professional communication, the majority of higher schools in Poland (both universities and polytechnics) do specialist language courses. A professional should be well-versed with their field of knowledge, but also should have a tool to expressed their ideas in a language that is commonly used internationally. It is often emphasised that teaching a professional language (usually English) distinguish higher schools from secondary ones. But the point is not to differ, but to bring something useful, which can be applied in a future job, and to give good results. When asked in a survey, students of the university of Warmia and Mazury were in their $3 / 4$ in favour of a professional language, instead of general one. It shows clearly that the awareness of the importance of a specialist language in a professional life is common. It is even more valuable that this consciousness is on the part of the students which is a guarantee of good teaching results.

\section{Professional background}

The author has been a language teacher for over 25 years now. His main interests in his job are: teaching special needs students that gives him a great deal of satisfaction, and doing specialist language courses, where the feeling of usefulness is a motivation enough. The author specialises in technical subjects (mechanics and the machine industry, building engineering, computer science) but from time to time also in medicine, and namely nursing. He is a graduate of a 3-year vocational school for mechanics and drivers in Olsztyn. Hence he has a good, basic knowledge of technology. As his interest in the technical field is authentic and sincere, the author is au courant with its latest achievements.

Witnessing a genuine familiarity with their specialisation, the students are more willing to cooperate, they get involved easily in the activities which they usually find very interesting. Often it is the task of the students to propose and prepare materials they consider the most relevant and the most useful. When fully involved in the classes they learn without noticing any effort they make, and the process of teaching becomes two-directional, the teacher passes his knowledge to the students, and reversely they also teach him. It is worth noticing that the author is appointed a language examiner for Ph.D. candidates at the Faculty of Mathematics and Computer Science and has performed the functions for many years now. He also wrote six syllabuses for teaching special-purpose English for mechanics, building engineering and computer science students (in each case both for the upper intermediate and advanced level). All the syllabuses consist of 30 hours of classes each, they contain fully original, prepared by the author exercises, as well as answer keys.

\section{Presence of foreign firms}

The common presence of foreign firms on the Polish market is an stimulus for the students to work hard in order to master the language. Seeing the perspectives of being employed in one of them motivates the students to learn even more and more effectively. It is a blessing for Polish students that they see a sense in their efforts, expecting a good post offer in an English-speaking work environment. A good command of the language opens up new opportunities and is perceived as one of the most important assets of a future employee. On the other hand, an inadequate knowledge of English is often a hindrance on the way to climb up the career ladder and even in getting a job. A knowledge of the language has become a tool in an everyday operation of many enterprises. Telephone conversations, email correspondence, offers and invoices are often dealt in English. It is the task of a language teacher to prepare their students successfully for all of these challenges.

\section{Regular classes - case studies}

The author has conducted special-purpose English classes for over 25 years now. The secret of his success in this field seems to originate from two sources. The first one is a familiarity of the domains he deals with during classes, the second one is a serious approach to the duties, and first of all to the students. An obvious proof of these facts are: the popularity of his courses (the internet lists of his courses are filled up within minutes) and the results of his students as expressed in the independent final exams tests. To perfectly honest, this feeling of contentedness of the students is a cause of satisfaction to the teacher, which motivates to work even harder.

\section{A. Mechanics and Machine Industry}

The characteristic feature of English, as surely of many other languages, is a proliferation of fixed grammatical collocations. It seems to be the main obstacle to master the language [5]. It is not enough to learn vocabulary, because a verbatim translation, word for word is not possible. Thus the necessity arises to learn vocabulary in an appropriate context. A common mistake is the use of a wrong word, most often a verb, which leads to misunderstandings. These difficulties can be easily observed in an oral utterances and in writing essays, yet they are easiest to be met in translation work from a mother tongue to the target language. 
But apart from difficulties there are phenomena which facilitate the process of learning the language. One of the most important is motivation. The students are very aware of the necessity of knowing English, thus they are determined to work hard in order to reach this goal. Unfortunately, determination is sometimes not enough when the ability does not match the will. Certainly, in the case when the student has not got a perfect linguistic talent, a strenuous effort can compensate this deficiency:

\section{B. Building Engineering}

Here again motivation is usually not a problem. Employers are concerned to have labourers who can work in international teams or to have staff members in a foreign firm. It is quite common that polish enterprises cooperate with foreign firms and send their workers abroad for a professional training. Good communication skills in all the abovementioned situations is decisive for a business success. An insufficient knowledge of English can eliminate a job applicant or may be a reason for redundancy in the case of a worker.

The use of paraphernalia, job advertisements, clips of articles, written instructions, firm profiles, often does the trick of even a better involvement [1]. The psychological certainty that all these materials are real, not fabricated only for the need of teaching enormously facilitates the teaching process. It is advisable to get the students involved in looking for such materials. They know best which information and what forms of paraphernalia they find the most interesting. Sometimes their innovation can prove to be surprising and totally unexpected but in a positive sense. The more freedom one gets, the more ingenious they can be. Any language is a complex, complicated system, which should not be presented in only strict, grammatical formulas. It ought be rather personified to sound natural, to express what the person really means.

You can encourage students to prepare their own leaflets, advertisements, commercial slogans, depending upon their language level and in accordance with their interests. Searching materials they surely will find something which is going to focus their attention and will be an urge for a further inquiry. Show that you are interested, the students will certainly follow. And a proper pace of activities, adopted to the ability of the group will contribute to a success.

\section{Computer Science}

The very fact that the USA is the global leader of IT solutions, both in the field of computer hardware and in programming naturally predestines English to the role of an It lingua franca. Hence it is easier to draw information from original sources than in the form of translated materials. The problem that may occur is the quality of translation and possible abridgements. On the other hand, some materials are never translated and the only way to read them is doing it in the original. A personal contact with a specialist is much easier without involving an interpreter. And when it does happen, some information can be missed or misunderstood because of using an intermediary.

A quick access to information via the internet is often limited by the use of English only by publishers. It is simply unrealistic to expect native speakers of English to go to the trouble to write materials in a foreign language. Only these reasons, as well as many others that have not been brought forth here, cause that motivation of the students can be taken for granted. These circumstances make teacher's work easier and more effective. The students work willingly as they want to succeed in their future jobs and the way is through English.

\section{Nursing}

In the Polish educational system nursing stands closest to practice, as it is obligatory for the students to do the theoretical part of the course in combination with an apprenticeship. The practical part of the course is done either weekly (usually two days in a week), or at one go in year (usually two months). The differences depend upon an individual approach of a given university or academy. Thus it can be said that these students are partially regular students and partially workers, anyway they certainly have part-time jobs. Their professional training is meant not as an observation what professional nurses do, but pragmatically to watch and do. No wonder that they very quickly acquire skills and experience. After some time they have already the routine of calm behaviour in critical moments and manual steadiness.

The main problem to manage nursing classes is often their fatigue.
Combining a difficult course in medicine with almost a regular job is not easy at all. There is not enough time for relax. Depending upon an individual character of stamina of a given student, such "relax" can be either a theoretical course at a university or practice in a hospital. No matter how jokingly it may sound, it proves to be true for some extent. And here is the role of the teacher to conduct classes at a such pace and using such methods and aids as not to add to the feeling of weariness. Although it is complicated, but as the author's experience have showed, feasible.

\section{Methods}

As a method of research descriptive statistics was applied. The data of the last five years was gathered in the form of a comparative analysis. As a synthetic way of showing the results of teaching the system of grades was chosen. Although a bit subjective, it shows clearly and in a simple way the changes in the level of knowledge within this period and the trend of learning achievement which has occurred.

Specialist language classes are conducted at the author's university as 30 hour courses at the level of master studies in the fourth or fifth year. The scale of grades which is commonly used at the higher school level consists of 6 marks: very good $=5$, good plus $=4.5$, good $=4$, satisfactory plus $=3.5$, satisfactory $=3$, and the failing mark $=2$. There is no excellent mark, and if it is given, the use is simply illegal. But contrary to universities, in primary and secondary schools the excellent grade (i.e. 6) belongs to the standard marks scale. Unfortunately, the author is not authorised to publish the actual data in the form of a table.

\section{Results}

The results show clearly an upward trend in the teaching achievements When the numbers of the best marks are compared, between the first (i.e. 2012/13) and the last year (i.e. 2016/17) of the analysis, it turns up that in the case of the specialisation of Mechanics and the Machine Industry there is an considerable increase. In turn, a comparison of the numbers of the lowest marks proves that the groups of the Mechanics and the Machine Industry did improve the result between the first and the last year of the analysis. The respective results for the other groups were also favourable. All in all, the students did splendidly.

\section{Conclusion}

Although teaching a special-purpose language demands an additional effort on the part of a teacher, the results that it brings are a fair reward for this supplementary work. In the case of general language groups the classes are conducted according to the textbook material, while a specialist language groups teaching is most often based on the instructor's materials. Because of the common involvement of the students in specialist groups, it is easier to have their attention and to achieve better results than in the case of regular, general language groups. It is simple to get the student do role play activities, to conduct a discussion, do a teamwork, or make them prepare their own materials.

Although English is only a tool in technical professions, it facilitate exchange of information which is of great importance in today's world when numerous enterprises cooperate with foreign firms or belongs to international companies. Students are very much aware of these circumstances and work more and more willingly to join the community of world's professionals.

\section{References}

[1] T. Dudley-Evans, M. St John, Developments in ESP: A multi-disciplinary approach. Cambridge University Press, Cambridge (1998).

[2] T. Hutchinson, A. Waters, English for Specific Purposes: A learningcentred approach. Cambridge University Press, Cambridge (1987)

[3] P. Robinson, ESP Today: a Practitioner's Guide. Prentice Hall International, Hemel Hempstead (1991).

[4] P. Strevens, ESP after twenty years: A re-appraisal. In: ESP: State of the Art. Red. M.L. Tickoo. Seameo-Relc, Anthology Series 21, Singapore (1988). [5] H.G. Widdowson, Learning Purpose and Language Use. Oxford University Press, Oxford (1983).

[6] M. Bracaj, Teaching English for Special Purposes and Teacher Training, Aleksander Mosiu University (2013).

[7] Milevica Bojović, Teaching Foreign Language for Specific Purposes, Teacher Development, Čačak (2013)

[8] A. Valeria, General View on the Relationship between ESP and EGP, Politehnica University of Timisoara (2014). 